\title{
Playing (Un)Dead: Interrogating Invocations of 'Monster' Met- aphors in (Post-)MMT Service User Narratives of Methadone, Maintenance and Treatment
}

\author{
Christopher BR Smith* \\ School of Social Work, St. John's College, Memorial University of Newfoundland, Canada
}

*Corresponding author: Christopher B.R. Smith, Ph.D., Assistant Professor, School of Social Work (Cross-Appointed Community Health and Humanities, Faculty of Medicine), St. John's College, Office: J-2009a, Memorial University of Newfoundland, St. John's, NL, A1C 5S7, Canada, Tel: 709-864-7701

\begin{abstract}
Background: From social productivity to social costs to clinical stability, traditional outcome measurements employed in methadone maintenance treatment (MMT) serve to reinforce binary oppositions between sickness and health, 'dirty' and 'clean', stable and chaotic, life and death. Such binaries thus position the (post-)MMT service user according to a series of fixed axes that are in turn reproduced in popular and professional discourse. Destabilizing these binaries, 'monster' - and particularly zombie or 'undead'metaphors have been a persistent feature of MMT culture since its inception in the 1960s. This paper thus argues that metaphorical invocations of zombies in (post-)MMT service user discourse functions as a regenerative trope, eroding the binary foundations of MMT.
\end{abstract}

Methods: Based on a comparative, qualitative, ethnographic analysis of two high-volume methadone clinics - one in Toronto, Canada and the second in Philadelphia, Pennsylvania (U.S.A.), this paper draws from qualitative interviews with 20 (post-)MMT service users, broadly defined as individuals with experience of methadone tapering or treatment discontinuation.

Results: Analysis reveals three primary contextual deployments of zombie metaphors in (post-)MMT service user discourse, functioning as (1) A tactic of boundary negotiation; (2) A tool of critique; and (3) A means of articulating post-treatment 'after-lives'.

Conclusion: 'Undead' monster metaphors in (post-)MMT service user narratives represent both a product of - and a destabilizing threat to - the binary foundations of traditional MMT discourse. Revealing a range of liminal subject positions in the reductive 'life and death' stakes of methadone treatment, findings reveal how undead metaphors embody a reflexive space through which users re-negotiate identity, agency and autonomy. Exhuming users' agency and 'political pharmacology', analysis demonstrates three interrelated themes characterizing users' tactical discursive deployments of the undead: (1) Relapse as resistance; (2) Recovery as radical reassertion of autonomy; and (3) Harm reduction as anarchist practice.

\section{Keywords}

Methadone, Metaphor, Liminality, Harm reduction, Identity

\section{Introduction}

Zombies, cyborgs, 'Being-maintained', and other metaphors of monstrosity

[T]he place [traditional Haitian] zombification holds is strikingly similar to that of antipsychotic drugs in Western psychiatry (a similarity whose aptness may be reflected by our tendency to describe a patient on antipsychotics as "zombified"). In that sense zombification is a surprisingly modern way of dealing with undesirable behaviors [1].

In 2009, the Canadian Centre for Addiction and Mental Health [2] produced an anti-stigma campaign entitled Methadone Saves Lives ${ }^{\mathrm{a}}$. Describing methadone maintenance treatment (MMT) as a 'life saving' intervention, CAMH's [2] campaign thus effectively perpetuates one of the central binary oppositions underlying MMT discourse, implicitly suggesting that illicit heroin use kills, and untreated opiate dependence inevitably leads to death [3].

aSee http://www.methadonesaveslives.ca/

Citation: Smith CBR (2018) Playing (Un)Dead: Interrogating Invocations of 'Monster' Metaphors in (Post-)MMT Service User Narratives of Methadone, Maintenance and Treatment. Int Arch Addict Res Med 4:028. doi.org/10.23937/2474-3631/1510028

Accepted: August 21, 2018: Published: August 23, 2018

Copyright: (C) 2018 Smith CBR. This is an open-access article distributed under the terms of the Creative Commons Attribution License, which permits unrestricted use, distribution, and reproduction in any medium, provided the original author and source are credited. 
Here, not only was the object of drug addiction (i.e. heroin) depicted as deadly, but untreated heroin users were similarly constructed as dangerous, posed as an abject, inherently transgressive threat, in contrast to the life-saving medical intervention of MMT [2-8].

Originating in the work of Turner [9], the notion of liminality constitutes a state of being that is "neither here nor there", but "betwixt and between". Tracing the social symbolism of metaphorical invocations of monsters and/or monstrosity in MMT service user - and provider - discourse [10], this paper works to demonstrate how such metaphors function in the specific context of MMT tapering and/or treatment discontinuation by utilizing a critical analysis of the traditional binary foundations of MMT discourse to interrogate metaphors of liminality in (post-)MMT service user narratives of 'zombies', the 'walking dead', and/or other non/post-human forms of what Ronell [11] termed "Being-on-drugs". (Re-)mapping a wide array of monstrous figures as they manifest in (post-)MMT service user metaphors, the paper begins by illustrating the various ways that North American MMT policy is implicated - and complicit - in the creation of monsters. Second, by focusing on a critique of the prevailing pathology paradigm (or biomedical 'brain disease' model) of opioid dependency, the work argues that users' apparent inversion of MMT binaries in fact articulates a multiplicity of new subject positions that are simultaneously both "animate and inhabitable" [12]. Asserting that (post-)MMT service users' tactical deployment of 'monstrous' metaphors represents the emergence and proliferation of new forms of posthuman 'anti-subjectivity', the paper moreover reveals new insights into not only the exercise of power in late-capitalist society, but moreover the historical succession of Western civilization's "subjugation and oppression of its 'Others' [13].

As Haraway [14] reminds us, "[m]onsters signify" (p. 117), and metaphors of monstrosity signal a clear threat to fixed subject/object designations. Not unlike the cyborg, that other 'monstrous' figure so central to contemporary pop culture, Lauro and Embry [13] suggest that the zombie symbolically "crashes borders" and is thus "defined by its liminality". In sharp contrast to representations of the liberated cyborg subject [15], however, the undead are directly equated with enslavement, eerily resonating with early historical definitions of the term 'addict'/addiction $[16,17]$. Because "individual consciousness" and "personal agency" are integral to human self-definition, in other words, the (often gendered) figure of the zombie [18] conjures something "subhuman, animal", where "to be a human without agency is to be a prisoner, a slave" [13]. Animate, yet lacking either agency or affect. Drawing on Butler, [5] metaphors of monstrosity thereby designate bodies 'marked $[b y]$ death'.

Evidencing a range of liminal (post-)MMT subject positions in the reductive 'life' and 'death' stakes of addiction/treatment, this work argues that undead tropes embody a reflexive space to re-negotiate questions of being ${ }^{\mathrm{b}}$, identity, agency, affinity and autonomy, thus reimagining what one (post-)MMT service user termed "life after liquid handcuffs" (Danielle, Toronto). Ubiquitous among MMT service users across North America, where liquid methadone is typically administered orally, the term 'liquid handcuffs' clearly conveys not only users' perceptions of the punitive, disciplinary dimensions of MMT, but also the fluid nature of control that characterizes MMT policy and practice $[8,19]$. Revealing user-driven forms of harm reduction within the fluid control matrix of addiction/treatment as a literal case of users "fighting for [their] lives" [19,20], the work additionally demonstrates how recovery is rearticulated by many (post-)MMT service users in the terms of reclaiming autonomy, and peer-driven forms of harm reduction are situated as anarchist practice $[21,22]$. Here, metaphors of the monstrous/undead contain recurrent emphasis on affinity and direct action that work to directly implicate biomedical authorities and institutions in the creation of monstrous, undead, liminal, hybrid, posthuman subject(ivitie)s [9,20,23-25].

Drawing from a wide range of theoretical materials, a critical review of relevant scholarly literature regarding service user experiences of MMT, along with qualitative interviews and participant-observation ethnography, this work serves to 'exhume' and/or 'resurrect' the inherently political dimensions of MMT. This is accomplished by examining how metaphors of the monstrous/undead function as a tool for (post-)MMT service users to re-inscribe normative MMT binaries, re-articulate (posthuman) identities, re-assert autonomy, and re-negotiate fluid forces of control. Investigating not only how metaphors of monstrosity function in (post-) MMT service user discourse, but also how biomedicine is directly implicated in producing monstrous, 'undead' subjects, analysis suggests three primary functions of such metaphors among (post-)MMT service users. Each invoked under different circumstances to accomplish different objectives, the three primary applications of such metaphors include: (1) The tactical negotiation of boundaries, demarcating the (permeable) borders between self/other and self-as-other; (2) The critique of biomedical authorities and institutions, shifting blame and responsibility to MMT policy, practice, and pharmacology, and; (3) The articulation of post-treatment 'after-lives'. Examining (post-)MMT service users' autonomy and agency by interrogating the 'place' of monstrous/undead metaphors in (post-)MMT service user discourse, findings from this analysis reveal three interrelated themes: (1) Relapse as resistance [26]; (2)

'Or, playfully extending Ronell's [11] notion of 'Being-ondrugs'. perhaps zombie metaphors in (post-)MMT service user discourse more accurately depict an indeterminate, liminal space of existence best termed Being-maintained, be it through methadone, heroin any other dependency forming (illicit) substance or (medical) substitution [38]. 
Recovery as radical reassertion of autonomy [22,27-29] and; (3) Harm reduction as anarchist practice [21,22].

\section{Literature Review: Methadone, Maintenance, Treatment and Liminality}

'Unlike Donna Haraway's “Cyborg Manifesto”, we do not propose that the position of the zombie is a liberating one - indeed, in its [...] metaphors, the zombie is [often] a slave' [13].

Institutionalization of the biomedical 'brain disease' model for addiction research and treatment is now so prevalent across the world that it "possesses its own self-legitimating ideology", and has thus become hegemonic [30]. Correspondingly, the various outcome measurements used to gauge the success of MMT - from social productivity [31], to social costs [32], to clinical stability [33] - all articulate simplistic binary notions of sickness and health, poison and cure, 'dirty' and 'clean', medicine and drug, stable and chaotic, life and death [34-36]. A spectre hovering above the simplistic binary opposition between 'chaotic', 'non-productive' (and inherently 'destructive') illicit heroin 'addicts', and 'stable', 'productive', 'compliant' MMT 'clients' or 'consumers', users' invocations of the monstrous/undead reveal questions of liberation and dependency, agency and autonomy [28,34-39]. Problematizing the relationship between 'addiction' and 'consumer culture' [16,40-42], the author eschews the terms 'client' or 'consumer', instead employing the fundamentally more fluid term (post-)MMT service user to encompass past and present MMT service users, harm reduction service users with no desire for abstinence, and the potentially infinite number of liminal identities "betwixt and between" [9].

As a useful complement to the notion of liminality, the concept of the palimpsest serves to render transparent the dynamic, interdependent, mutually constituting relationship between space, subjectivity, and ('illicit') substance $[8,28,43]$. Derived from Ancient Greek, the palimpsest constitutes a writing surface that can be erased and written over, yet always maintains traces of earlier marks and imprints [22,28,43-45]. Positioning the urban environment as palimpsest, Harvey [44] describes the city as "a series of layers constituted and constructed at different historical moments all superimposed upon one another". In the context of this discussion, however, the notion of the palimpsest can be applied with equal conceptual relevance to both space and subjectivity, where ('foreign'/'illicit'/'controlled') substance is positioned as the medium of inscription, creating traces of identity that become over-written yet never fully disappear $[22,28]$.

Recently employed to describe the global economic climate in the terms of 'zombie capitalism' $[13,46,47]$, undead metaphors have featured in debates regarding

'Defining 'zombie capitalism', Hall [46] writes "since mid-2007, a hoarde of zombies has been shambling after the global economy, flailing at the doors and moaning 'brains'". For more on 'zombie capitalism' see Hall [46]; Harman, [47]; Lauro and Embry, [13].
MMT since its inception in the 1960s. Early critics posited the emergence of MMT as "an insidious form of social control aimed at turning inner-city minorities into harmless zombies" [48], or what [49] termed 'docile bodies'. Describing users' accounts of MMT enrolment as a "transition from 'righteous dope fiend' to 'zombie'", Koester, Anderson, \& Hoffer [50] suggest users' fear is "based as much on the institutional forces controlling the drug as the drug itself", while Hunt, Lipton, Goldsmith, Strug, \& Spunt [51] revealed undead tropes in users' accounts of ancillary drug use.

Recent literature has explored MMT treatment identities by employing theories of self-presentation and discourse analysis [52], narrative and non-user identity construction [53], agency and dependency [39], conformity and resistance [54], abjection and normalization [3], and actor-network theory [36]. Throughout the clinical literature on 'leaving methadone treatment' [55] there is repeated emphasis on high relapse statistics, positioning opiate dependence as a chronic, recurrent, life-long 'brain disease' [55-62]. In spite of the biomedical evidence supporting 'reasons for not trying to quit methadone' [59], a 2001 cross-sectional study in Australia [62] demonstrated that more than $70 \%$ of the sample $(n=871)$ reported 'considerable interest in withdrawing from $\mathrm{MMT}^{\prime}$ (p. 123). Although there has been little investigation into MMT detoxification outside formal treatment settings [63,64], Noble, et al. [63] investigated self-detoxification efforts among $66 \mathrm{MMT}$ service users in Britain, noting a high prevalence of both attempts and successes.

Central to this analysis, the concept of liminality was first popularized by Turner [9] to describe the ambiguous middle stage in traditional rites of passage. More recently, this concept has been adopted throughout the social sciences, where contemporary investigations have traced the relations between liminality and stigma [65], spatialization [66], identity (re-)construction [67] and the dissolution and imposition of 'order' [68]. As a poignant political trope premised on an 'animate and inhabitable' [12] state of liminality [9,65,69], undead metaphors in (post-)MMT user narratives reveal evidence of anarchist-oriented political praxis, grounded in the principles of autonomy, affinity and direct action $[20,21,23-25,28]$. Illustrating the explicitly political dimensions of 'recovery' in the 'life and death' stakes of addiction/treatment, this work investigates how invocations of the liminal undead destabilize the fixed binary foundations of MMT, thus revealing the fluid, shifting subject position of the drug/service user.

As valentine [36] asserts, traditional MMT research conjures a liminal 'netherworld' where subjects are 'no longer addicts but [...] no longer straight', negotiating a state of terminal limbo between 'addicted' and 'autonomous' (p. 512). Throughout popular and professional, clinical and user-based discourse, the stability/ 
chaos binary thus serves to position drug/service users according to a series of fixed axes that are in turn reproduced in artificial invocations of liminality [34-36,39,48]. Problematizing the overreliance on Foucault's theory of biopolitics in MMT research [35], this essay furthers Fraser and valentine's [38] work concerning the multiplicity of MMT identities to focus on one specific sub-group of "dissatisfied [MMT] consumer[s]" - the (post-)MMT service user - to argue that users' invocations of the monstrous/undead serve as a productive trope, functioning to erode and destabilize the binary foundations of MMT by (re-)inscribing a multiplicity of positions in between.

\section{Methodology: Reframing the Political Dimen- sions of Addiction/Treatment}

[A] cyborg world is about the imposition of a grid of control on the planet... From another perspective, a cyborg world might be about lived social and bodily realities in which people are not afraid of their ... permanently partial identities and contradictory standpoints. The political struggle is to see from both perspectives at once because each reveal both dominations and possibilities unimaginable from the other... [15].

\section{Design}

Interview data was collected over the course of the author's doctoral and postdoctoral research. In the first case, the author undertook six months of ethnographic fieldwork and conducted qualitative interviews with service users and community members surrounding a methadone clinic that was relocated into a rapidly gentrifying neighborhood on the periphery of downtown Toronto, Canada. In the second case, during the author's postdoctoral work at the University of Pennsylvania, the author undertook an additional six months of ethnographic fieldwork and interviews at a high-volume methadone clinic in inner-city Philadelphia in an effort to comparatively analyzed the ideological underpinnings of MMT in North America.

This paper therefore draws from qualitative interviews with (post-)MMT users, broadly defined as subjects with experience 'leaving $\mathrm{MMT}^{\prime}$ [55]. Although many users retained some degree of in/formal involvement in MMT, the term (post-)MMT user is employed in reference to $\mathrm{MMT}$ subjects who have had experience with tapering and/or treatment discontinuation. While the larger post/doctoral project involved interviews with 57 MMT service users (34 Canadian and 23 American), this essay focuses on the $35 \%$ of users $(n=20)$ who explicitly referenced methadone tapering/detox during open-ended, semi-formal, tape-recorded interviews. Among the sample, $80 \%(n=16)$ maintained some degree of in/formal involvement in MMT; of the four individuals who had completely discontinued MMT, one was transitioned to buprenorphine, two returned to full time heroin use, and the fourth professed issues with alcohol.

\section{Sampling and recruitment}

The Canadian cohort consisted of seven men and four women, while the U.S. cohort consisted of five women and four men. Participants' age ranged from 24 to 72 years, with a median age of 39 . With the exception of two African-Americans in Philadelphia and one Iranian-Canadian in Toronto, all interview participants self-identified as 'white'. During daily field visits to each methadone clinic the author developed relationships with many research subjects, and conducted interviews in a variety of settings, ranging from cafes to clinic offices. Recruitment was facilitated by key informants in both cities who were introduced to the author through research contacts at the Canadian Harm Reduction Network and the U.S. Harm Reduction Coalition, subsequently following a traditional snowballing recruitment method.

Serving approximately 400 MMT service users, over the course of Canadian fieldwork (May - November, 2007), the relocation of the Toronto clinic became the focus of fierce community opposition, generating national media coverage and contributing to widespread moral panic regarding MMT in the province $[7,70]$. Serving approximately 700 users, the Philadelphia clinic was similarly located in a transitional, gentrifying neighborhood. Although there was no concerted campaign of community opposition, during U.S. field research (June - December, 2010) several inflammatory articles regarding the clinic appeared in local community newspapers. Evidencing the perceived de-humanizing effects of MMT, one article described a service user "stumbling", with "erratic movements [...] at irregular starts and stops... unsteady on his feet" [71]. Describing the effects of methadone as being "nearly identical to heroin", the article went on to state that "[t]he problem [...] is that the patients leave the hospital 'high' on methadone", with the "sheer amount of intoxicated patients" keeping the local beat cop "on his toes" [71]. Detailing the thriving prescription drug market at a coffee shop adjacent to the clinic, the article then referenced the janitor at the nearby library, who was forced "to kick out at least two 'nodders' - as he called a person under the influence of methadone" [71].

\section{Data analysis and ethics approval}

All interviews were conducted, transcribed, coded and analyzed by the author. Analysis of post-MMT service user transcripts took an iterative form, with key themes emerging through the author's transcription and detailed re-reading of the material. Here, undead metaphors were defined as encompassing (1) Literal references to 'zombies', 'monsters' or 'the (un)dead'; (2) Invocations of reduced agency related to MMT policies and regulations, and (3) Allusions to the role of methadone in the numbing or 'deadening' of affect. This pa- 
per interrogates liminal undead metaphors deployed by (post-)MMT users' by utilizing both discourse analysis and deconstruction, tools that have proven particularly salient in interrogating the binary foundations of drug discourse [36,52,72-75]. Informed consent was collected from all research participants and pseudonyms were used to ensure anonymity and confidentiality. Toronto interviews were conducted with ethics approval from York University, while the Philadelphia research was undertaken with ethics approval from the University of Pennsylvania.

\section{Results}

If methadone helps you to lead a normal, active and happy life, then it is well worth the inconvenience, the side-effects, and any possible stigma you may encounter... [76].

[M]onsters betray a distrust and discomfort with certain kinds of bodies [13].

\section{The walking dead: Boundary creatures and thresh- old-scapes}

Springing from popular and professional binaries between methadone and life, heroin and death, (post-) MMT users' in/direct references to the undead often functioned as a vehicle of delineation, articulating boundaries between the 'non/infected' self and other. Here, the deployment of zombie tropes served to not only demarcate the undead other, but also to describe various phases of self-transformation attributed to methadone, the pharma-techno - "prosthetic substance of substitution [38]. As post-MMT service user narratives indicate, the latter might best be demonstrated by Houborg's [77] notion of political pharmacology", defined as the user-driven contestation of how methadone and heroin are dominated by "medico administrative technocracy", explicitly focusing on how drug/service users, 'engag[e] not only in political questions' relating to methadone and heroin, but also espouse 'technical and epistemological questions about [...] what constitutes reliable and relevant knowledge' regarding said substances (p. 155-56):

Instead of 'liquid handcuffs' I always thought of methadone more as a 'liquid lobotomy' because it numbed my subconscious (Evan, Toronto).

Mentally methadone turns you into a sloth. If you keep going up and up you're just chasing the high, which defeats the purpose (Jeremiah, Toronto).

While Evan's narrative positioned the everyday state of being-maintaine ${ }^{\mathrm{d}}$ as a numbing experience implicitly likened to zombiedom through the negation of affect,

\footnotetext{
d'Being maintained' playfully borrows from Ronell's [11] Heidigger-inspired notion of 'Being-on-drugs', where as she writes: 'Addiction will be our question: a certain type of "Being-ondrugs" that has everything to do with the bad conscience of our era'.
}

Jeremiah invoked dose as a dependent variable, a sentiment echoed by other interview participants:

Here they'll put you up to $700 \mathrm{mls}$ - I saw a girl who said she was on 700 . I thought I was high at 200 , but who could function on $700 \mathrm{mls}$ ? The girl couldn't even keep her eyes open. She was like the walking dead - zombies, you know? (Bill, Philadelphia).

As Bill suggests, exceptionally high doses of methadone are perceived by some users' as resulting in the obstruction of the subject's cognitive abilities and affective capacity, negating agency, and thus her very humanity $[13,34]$. Containing an implicit structural critique, Bill's narrative both implicates MMT policy, and the clinic itself in the production of monsters. Other users also cast MMT culture as a causal factor, posing the clinic as a zombie 'breeding ground' (Benny, Philadelphia):

What does the clinic have in common with reality? When you get on [MMT] it's suddenly this new scene where people start taking [benzodiazepines] and all that shit, and they lose control. And you gotta come down to the dope neighborhood everyday with 700 other dopefiends to get medicated, so if you wanna clean up, is this really the place to be? (Eleanor, Philadelphia).

Eleanor's portrayal locates MMT as a liminal simulacrum existing between the world of the 'righteous dopefiend' $[4,78]$ and the equally illusory 'real world' of the workaday 'nine-to-five' $[4,75,78]$. Signaling the negative repercussions of socio-spatial segregation in MMT $[7,8,79]$, Eleanor poses ancillary drug use as a direct symptom of MMT culture $[8,34]$. Providing users with a tactical means of problematizing the stable/chaotic binary, undead metaphors effectively posited 'pill-heads' as 'unstable' zombies seeking to obliterate cognition and affect, providing users with a tactic of subverting the stable/chaotic binary [51]. Indirectly conjuring sub-human subjects in descriptions of the deadening effects of ancillary drugs, such narratives resonate with Lauro and Embry's [13] assertion that the zombie constitutes an "antisubject ... wholly devoid of consciousness" (p. 89):

When I was first on [MMT] I really took it to the maxpills, dope, everything. I was like a human garbage disposal, you know?... But now I'm doing better: I won't shoot dope, and I won't take Catapres ${ }^{\circledR \mathrm{e}}$ (Jill, Philadelphia - emphasis added).

Jill's depiction of her early MMT experiences morphed from physical to figurative forms of waste, although her concluding remarks suggest the reclamation of her once disposable life. Calling back to its origins in Hatian folklore, Lauro and Embry [13] assert that the

eThe U.S. trade name for clonidine, Catapres $^{\circledR}$ is an antihypertensive drug used to treat high blood pressure. Historically used in medical opiate detox, MMT users in Philadelphia used clonidine recreationally, claiming it served to 'potentiate' methadone's effects. 
"collapsed subject/object status" of the zombie represents its most distinct feature, denoting both automaton and slave (p. 100). As a vehicle of self/other delineation, therefore, undead tropes worked to highlight the relinquishing of agency perceived to accompany treatment enrollment:

[Staff] use methadone against you, like you gotta submit, and people are so afraid to challenge them 'cause they don't want to go sick. You have no control with methadone, but with heroin you do (Eleanor, Philadelphia).

Subverting the normative binary foundations of MMT, Eleanor's allusion to 'submission' conjures the neoliberal mantra 'free to choose' [41], positing heroin as the ultimate form of consumer freedom. Other users, however, simultaneously problematized the perceived freedom of heroin and the personal/political compromises attendant in MMT:

The program is positive because you don't have to worry about getting dopesick, but you're also like a puppet, you know? You gotta do what [staff] say, and if you don't you get kicked off. The program controls you, making it really hard to just live a normal life (Jill, Philadelphia).

Conveying the ontological ambiguity attending liminality, Turner [9] posed liminal entities as "threshold people" who must "obey their instructors implicitly, and accept arbitrary punishment without complaint" (p. 81). Depicting MMT staff as 'puppet masters', Jill portrayed the institutionalized dependence of MMT as a force that subsumes individual agency. Informed by the indeterminacy of treatment duration, mobility restrictions, and the perceived 'addictive' nature of methadone itself ([50] Amanda, Toronto; Benny, Philadelphia; Jill, Philadelphia), users' metaphorical allusions to the undead conveyed a crisis of agency created by inhabiting liminal subject positions, where the process of finding one's place in MMT was likened to being put in place:

Once you're on [MMT] there's no exit strategy - even 10 years later there's no planning to get off, no talk of what you might be doing after methadone, you know? (Benny, Philadelphia).

\section{Creating monsters: The zombie as tool of critique}

In a separate yet related contextual deployment, zombie metaphors in (post-)MMT user narratives functioned as a critical trope implicating MMT policy and 'political pharmacology' in the creation of monsters [77]. Attributing their de-humanizing loss of agency to MMT policy, users consistently emphasized the lack of institutional support or resources for tapering and/or treatment discontinuation:

My doctor never gave me the support I needed to get off and I felt controlled because he wouldn't taper me. There was no help anywhere - no peers or social support, you know (Danielle, Toronto)?

They have no follow up programs for anyone who quits [MMT], so basically, you're on your own. They need to have something for people who want to detox properly instead of just giving you the choice between going cold turkey or going back to [heroin] (Christine, Toronto).

Related to a perceived lack of exit strategies, the decentralized confinement produced by the socio-spatially segregated North American MMT landscape [8] resulted in user descriptions of feeling chained, stuck or trapped in a state of terminal liminality. As Lauro and Embry [13] have argued, because humanity defines itself according to individual consciousness - and by extension agency - 'to be a body without a mind is to be subhuman, animal... [and] a human without agency is [...] a prisoner, a slave' (p. 89-90). Arising from transgressions of the MMT service user-provider contract, here treatment expulsion can be seen as a form of exile to the land of the (un)dead, with detox protocols typically ranging from seven to 28 days:

I wasn't doing well, whatever doing well on methadone is, so I got kicked off the program because I was giving dirty urines every time and I got caught diverting [methadone]. Their detox was like falling off a cliff: from $90 \mathrm{mls}$ to zero in a week. So I started using junk again, but I couldn't get high and I spent all kinds of money (Benny, Philadelphia - emphasis added).

Exposing users' ambiguous perceptions of 'success' in a for-profit treatment system fundamentally premised upon continual enrolment (i.e. 'retention'f), Benny's experience illustrates the 'inhuman' super-capacity for opiates induced by rapid methadone detox, a method consistently associated with high relapse rates $[55,58,80]$. Here, (re-) situating the self-as-zombie-asvictim thus implicitly re-assigns blame to biomedical authorities. Shifting trajectories, other users emphasized the structural forces underpinning addiction, effectively repositioning recovery in explicitly political terms:

[MMT] is good at keeping you off opiates but doesn't do a great job of dealing with the reasons why you were using in the first place. Unless people get [counselling] from somewhere else, the moment [methadone] is taken away, the urge to use [opioids] becomes overpowering (Noam, Toronto).

At this clinic all you get is a script. It's not about helping - in fact, they want you to stay on. Just coming to get your [methadone] is not enough (Ewan, Toronto).

In Canada, where service users often colloquially referred to methadone as 'juice', the neoliberal reframing of medicine-as-business has been rendered by critics

'Here, in tandem with dose, 'retention' forms the primary measurement for 'clinical stability' [33]. 
through references to private, for-profit, group-practice MMT clinics as 'juice bars' [8]. Problematizing the sole reliance on methadone as a 'technocratic magic bullet' [34], such remarks contain overt criticism of the limited service, high-volume 'juice bar' model for MMT [8], tacitly resituating treatment as a form of zombie-dom in and of itself.

Popular and professional regimes of representation construct heroin as an inherently dangerous and destructive substance [3], positioning 'junk' as the catalyst responsible for creating monsters, and $\mathrm{MMT}$ as its antidote or cure. Re-framing this discourse, however, user narratives implicated biomedical authorities in the creation of monsters, thereby gesturing to the possibility of heroin to function as a tool of resistance and liberation:

My life after liquid handcuffs is far better. If I stayed on methadone I think the cancer would have killed me. I came out of remission three times while I was on methadone, and I only went back into remission when I started heroin again, so I didn't have any choice - it forced me into a position where I had to start selling [heroin]. I'm not young enough to be [stealing], so [dealing] was the answer. I'm not proud of it, but all my clients are adults, so... I'm not creating any monsters; I'm just accommodating a need (Christine, Toronto).

Subverting the normative binary between MMT as life-saving [2] and heroin as deadly [3], Christine depicted her transition from MMT back to using and dealing heroin in the terms of re-negotiating and/or reclaiming autonomy. The shifting place of who/what is monster in users' articulations of identity is here evidenced in the reinforcement of clear moral boundaries, where the 'monstrous' heroin dealer literally is a 72-year-old grandmother.

Demonstrating the potential of liminal undead metaphors to disrupt and destabilize dominant representations, further analysis of (post-)MMT service users' regenerative political pharmacology $[14,77]$ reveal new forms of experiential knowledge, illustrating an inherently illicit everyday lived identity that is both derived from - and continually rooted in - notions of autonomy, affinity and direct action $[20,24,25,31]$.

\section{Back from the (un)dead: Reincarnation narratives and post-MMT after-lives}

Bleeding between methadone pharmacology, socio-spatial segregation, and the fluid, continuous and decentralized manifestations of control inscribed in MMT policy and practice ${ }^{\mathrm{g}}$, (post-)MMT user narratives repositioned the creation of monsters as a process contingent

'A sign posted on the wall of the 'dosing room' at the Philadelphia MMT clinic provides an example of how control is inscribed in MMT: "The clinic is not a social gathering place ... ONCE YOU HAVE BEEN MEDICATED YOU MUST LEAVE HOSPITAL GROUNDS IMMEDIATELY, NO EXCEPTIONS ... The main focus of strictly enforcing the no loitering policy is the protection of a clients' right to successfully work on their recovery efforts" (from the author's field notes - original emphasis). on an interdependent, mutually constituting relationship between substance, space and subjectivity $[8,37,43,79]$. Locating the experience of MMT in the underlying inter/intra-activity between the substance of substitution (methadone), the space of converging control forces (the clinic), and the (quasi-)autonomous 'consumer' subjectivity of the treatment service user (the 'client'), zombie metaphors therefore played a subsequent role in the depiction of (post-)MMT 'after-lives', where narratives of reasserting institutional autonomy and reclaiming post-treatment identity were framed according to shifting invocations of 'rebirth' or 'reincarnation't. Demonstrating the conjuring powers of metaphor, such allusions served to clearly situate both space and subjectivity as palimpsests - sites of inscription that are continually being over-written, yet always retain the traces of earlier marks or imprints [22,43-45]. Here, in both historical and contemporary contexts, [45] asserts that the notion of the palimpsest is "inherently literary and tied to writing" yet can also be employed as a tool to analyze "configurations of urban space [...] unfolding in time". [45] focus on "reading palimpsests" is premised on the conviction that "literary techniques" have the potential to be "woven into our understandings of urban spaces as lived spaces that shape collective imaginaries", through the discursive vehicle of the metaphor, particularly as manifest in relation to notions of monstrosity.

Correlating to threats of treatment expulsion, returning to active drug use was thus in many cases posed as a liberating, voluntary form of reincarnation or self-reinvention:

'I ain't going to no group [counselling], so fuck it, I'm just gonna detox. They're gonna chop me down from $130 \mathrm{mls}$ in 10 days, but like I told [the nurse], my attitude is, "fuck it, l'll just get some dope". I don't believe that shooting dope is suicide on the instalment plan and all that bullshit. I have no desire to die and I'm not suicidal. Now if somebody comes back after they're dead and tells me that you can get high in the after-life, then maybe I'll think about it' (Eleanor, Philadelphia - emphasis added).

Borrowing from established binary associations between heroin and death, morally informed conservative rhetoric often likens harm reduction to a form of 'assisted suicide' [81]. Here, heroin users are constructed as abject bodies 'marked [by] death' [5] in a discourse that is less biopolitical than explicitly necropolitical $[82,83]$. Working to deconstruct the binary associations between heroin, chaos and 'death', treatment, stability and 'life', Eleanor's 'righteous dopefiend' attitude openly conveyed her willingness to walk away from the 'life saving' treatment that 'dissatisfied consumers' so often describe as enslaving $[2,4,36,78]$.

Drawing from metaphors of 'regeneration', (post-)

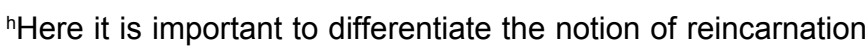
as it featured in accounts of the life and death stakes of MMT from the 'born again' trope associated with the abstinencebased 12-step movement and its uncanny likeness to the process of religious conversion [97]. 
MMT user stories framed in the fluid terms of 'reincarnation' - a state that may or may not entail complete abstinence or institutional autonomy - contained a central focus on tactical instances of affinity and mutual aid. Here, in spite of their general hostility toward biomedical authorities, several users cited examples of institutional support in the form of sympathetic service providers:

In the end [MMT] was so demoralizing and undignified that a light went on and I just said "it's over", and six months later I was off methadone. I went down $10 \mathrm{mls}$ a week in three months. I went from 10 to four and then just walked out. Dr. ---- really helped me believe I could do it. He had a great ability to rejuvenate me and make me feel human again like I wasn't a fucking cockroach, you know? I said 'I'm doing it', and he was the only one open-minded enough to go along with it (Evan, Toronto).

Acknowledging the critical rejuvenating, re-humanizing role of his physician, Evan's narrative contained an underlying tone of militant autonomy, where a personal revelation led to his successful treatment discontinuation, aided by a relationship of 'collaborative autonomy' with his sympathetic physician [27]. Emphasizing the supportive empathy of peers, and elevating the experiential knowledge of people with lived experience of 'substance and substitution' [27,38], affinity and mutual aid among users was a prominent feature of such narratives, resonating with contentions that drug users can and do serve as the primary agents of harm reduction practice [84-89]. Here, the 'logic of affinity' shifts attention to the 'revolution of everyday life', where individuals uniting under shared conditions of struggle can create spaces of autonomy beyond the gaze of institutional biomedical authority $[8,23,24,90]$ :

I had a good friend that helped medically detox me. I wasn't coming off [methadone] cold turkey-I tried that before and it didn't work. But this time I was lucky my friend was there to talk to me and give me the support I needed, medical and otherwise. Right now, I choose to stay [on heroin] - I could get off but it's not disrupting my responsibilities. I still have my dog, my apartment, the bills are paid, and hey, I enjoy it. I've noticed over the years that I've always maintained a job and a daily routine while using heroin as opposed to methadone. It was methadone that screwed me up and turned me into a crack-head (Danielle, Toronto).

I brought Danielle down from $100 \mathrm{mls}$. She asked [her physician] to detox her and he wouldn't do it. You ask them for help and you don't get it. There are no supports. If you haven't got friends with a bit of knowledge who are willing to help, you're fucked. But she and I have more freedom now than ever before. Danielle comes over here every morning, and we go out once a week. We're inseparable; people think we're married (Christine, Toronto).
Exploring the "political logic of the newest social movements", Day [24] suggests that contemporary activist practice has turned away from "universalizing conception[s] of social change", instead adopting "an anarchist logic of affinity" emphasizing direct action tactics (p.716). Individuals with shared experience (heroin use, MMT), and shared objectives (freedom from 'liquid handcuffs'), mutually supporting one another by utilizing their experiential knowledge of pharmacology, withdrawal, and MMT, Danielle and Christine's relationship can thus be conceptualized in terms of the basic tenets of social anarchism, namely affinity, mutual aid, and direct action. In both Canada and the U.S., (post-)MMT users' autonomous attempts at 'leaving MMT' (Magura \& Rosenblum, 2001) commonly involved re-negotiating a relationship to illicit substances, often resulting in re-scripting the normative binaries between the disorderly junkie and the complacent consumer $[35,36]$ :

My quality of life is definitely better. It's like life after death: I'm back from the dead. In the beginning I went on [methadone] because I wanted a free high, but now I'm just looking for something to ease my pain. I'm 56-years-old and I have degenerated disk disease. I have hep C, I've had a toe amputated and really bad foot pain, and I have a collapsed lung on the right side. So I'm just looking for something to kill the pain and make me feel comfortable - heroin does that for me but methadone didn't. (Danielle, Toronto - emphasis added).

Here, in Danielle's perception, returning to heroin was as a matter of practical necessity stemming from methadone's ineffectual nature in accomplishing clinical 'stability', pain management, or 'freedom' from illicit drug use.

The term monster, Haraway [14] reminds us, "shares more than its root with the verb to demonstrate" ( $p$. 117). As discursive vehicles of boundary negotiation, critique and metaphorical reincarnation, the conjuring of zombies thereby functioned as a trope for drug/ service users to articulate (post-)treatment subjectivity. Fundamental to the construction of post-treatment 'after-lives', liminal undead references therefore acted as a life-giving force in the depiction of life after 'liquid handcuffs' $[8,37]$ centrally informed by the notions of autonomy and affinity.

\section{Conclusion: Renegotiating fixed treatment identi- ties in a fluid landscape of control}

I therefore became an opium addict again because the doctors who cure-one should really say [...] who purge-do not seek to cure the troubles which cause the addiction [...and] my unbalanced state of mind [...] I preferred an artificial equilibrium to no equilibrium at all [91].

As perhaps the most demonized, dehumanized identity of illicit drug users, the 'monstrous' heroin user/ 
dealer haunts the public imagination [6]. Given the central role of disrupting binary oppositions through liminal articulations of (post-)MMT user identity, the conjuring of undead threshold monsters represents a product of the traditional binary associations between heroin, chaos and death, methadone, stability and life $[2,3]$. Trapped according to these fixed coordinates, users thus employed liminal zombie tropes to articulate a fluid and diverse range of subject positions, revealing instances of collapse in the traditional binaries underpinning traditional MMT discourse.

Sometimes manifesting as a return to the 'authentic' substance of dependence (heroin), users' deployment of reincarnation metaphors revealed subjects reanimated by forces outside the 'substitution' of MMT. As Fairbanks [26] suggests, in such contexts the notion of 'relapse' may reveal 'a broken contract between recovering technologies and the dreams of individual subjects' (p. 177). Described as a 'strategic alliance with a separate economy of knowledge/power' symptomatic of new, decentralized forms of control, the theme of relapse as resistance speaks directly to the plight of (post-) MMT users [26]. In a context where treatment is perceived as a 'life sentence', therefore, the metaphorical reference to coming back from the dead simultaneously implicates MMT in the creation of undead monsters and re-articulates heroin as life-saving alternative.

Building on relapse as resistance, the second central theme emerging from this research grows from the reframing of 'recovery' as a radical re-assertion of autono$m y$, revealing how user-based forms of harm reduction bear an uncanny resemblance to the political praxis central to contemporary social movements, or what Graeber [25] termed the 'new anarchists' [12,20,23,24]. Working to situate the fundamentally political origins of harm reduction as a literal case of fighting for our lives $[12,20]$, the notions of autonomy and affinity underlying user narratives effectively pointed to the third central theme of this investigation: harm reduction as anarchist practice [21]. In light of these findings, this project concludes by offering both a series of grounded policy recommendations, and one final illustrative reflection.

In the absence of accessible, acceptable treatment services, many drug/service users in this study resorted to autonomous forms of 'self-medication' [63]. As an institutionalized iteration of self-maintenance, MMT users in both Canada and the U.S. expressed the desire to be reclassified as 'pain management' subjects, and thus freed from the reward and punishment model of 'take away' doses and other perceived punitive aspects of normative addiction treatment regimes $[34,37,43]$. Decreasing the gap between the rigid restrictions governing addiction treatment and the relative freedom of pain management by investing drug/service users with more control over MMT is therefore a central recommendation [92].
An ongoing Canadian scientific trial premised on exploring viable alternatives to MMT, the North American Opiate Medication Initiative (NAOMI) 'Backgrounder' [93] begins by citing the deterrent nature of MMT program characteristics. Published data from this pilot study revealed higher levels of overall user satisfaction, suggesting that both pharmaceutical heroin and injectable hydromorphone (i.e. Dilaudid ${ }^{\circ}$ ) can 'effectively treat and retain opioid-dependent individuals currently outside the addiction treatment system' [94]. The institutionalization of heroin-assisted treatment (HAT) thus represents a second clear recommendation from this research $[4,34]$.

Shifting from self-medication to self-detoxification, owing to its long pharmacological half-life, tapering at low doses of methadone is often painful and statistically associated with exceptionally high relapse rates $[80,95]$. Resonating with users' convictions that methadone is 'more addictive' than heroin [50], the potential for transitioning individuals to short-acting opioids (i.e. dihydrocodeine) has been noted to have statistically higher rates of successful detoxification, exhibiting significant promise for reforming current methadone detox practices in North America [95]. Additionally, the potential role of ibogaine in opiate detoxification - unscheduled in Canada yet illegal in the U.S. - remains under-researched [96].

The zombie, as Lauro and Embry [13] remind us, is unconscious but animate, a creature absents of autonomy and governed by unholy outside forces of consumption (p. 91). As a symbol for our contemporary political-economic climate, the undead provides a rich source of metaphor, revealing the fundamentally destructive nature of 'zombie capitalism' $[13,46,47]$. In the present neoliberal era of our 'narcotic modernity' [75], the method with most potential for affecting social change is arguably direct action, described by Graeber [25] as 'a rejection of a politics which appeals to governments to modify their behavior, in favor of physical intervention against state power in a form that prefigures an alternative ${ }^{\prime}$.

While the hybrid cyborg in some ways functions to 'undo the tensions' of binary oppositions, the inimitable

iSet largely inside a shopping mall, Romero's [98] film Dawn of the Dead renders the relationship between zombies and capitalism stark. Asked why the zombies are congregating in the mall, one character insists 'They don't know why, they just remember [...] that they wanted to be here'. When asked 'what the hell are they?', he states: 'They're us'.

'Borrowing from Romero's [98] film, one form of carnivalesque anti-capitalist direct action against consumer culture has taken the form of 'zombie marches' in urban shopping malls, where activists don undead costumes and stagger zombie-like, equating contemporary consumerism to zombie-dom. Enjoying exponential growth in recent years, zombie marches have been applied to other forms of social critique as evidenced in websites advertising themselves as a source for all 'Zombie Flash Mob planning' (http://www.zombiewalk.com/forum/index.php). 
liminality of the zombie 'does not reconcile subject and object'; instead, as 'walking antithesis', it 'holds them as irrevocably separate', imploding binary oppositions in its lumbering wake [13]. Here, pop culture depicts the zombie as fundamentally dependent on the living for its survival, knowing only the unconscious pursuit of living flesh or 'brains', infection collapsing into the literal act of consumption [13]. Invariably constructed in the 'us-against-them' framework of a group of 'non-infected' survivors thrown together in a desperate struggle against the ubiquitous undead hordes, the central moral conflict common to pop cultural zombie narratives bears an eerie resonance to drug discourse: what do we do with one of our own who has become infected? An in-built reflexive pause follows the dramatic moment of consumption/transmission to signal the palpable inevitability of the situation before the scene then shifts to the inevitable scripted climax, where the monster that has been created is then mercifully 'put out of its misery'.

\section{Dedication}

Since the completion of field research and qualitative interviews, of the 20 interview participants whose voices appeared in the preceding work, at least eight have died from prescription drug interactions, opioid overdose, complications relating to HIV/AIDS and/or Hepatitis $\mathrm{C}(\mathrm{HCV})$, or the cumulative battle scars of the 'war on drugs'. As these individuals no longer possess the luxury of 'playing (un)dead', it is to them that I dedicate this work. That said, I am particularly indebted to 'Christine', who called for me from her hospital bed, half a continent away, during her final moments. Barely legible in faded blue ink beneath the fragile layers of her loose skin read the letters 'D.O.U.' An acronym for 'Dedicated Opiate User', these misshapen letters inscribed in flesh represented her most cherished tattoo, in and of itself a means of reconciling - and moreover embracing - her prosthetic subjectivity or state of being before the final dissipation that transpired in the space between her last breaths. Unable to shake the image of this inscription, I believe that in whatever plane of existence Christine now inhabits, she recognizes herself and her life in this work, albeit anonymized, and smiles (up? down? sideways? crookedly?) at all aberrant posthuman creatures, monstrous and otherwise, from the 'after-life'.

\section{References}

1. Morris H (2011) I walked with a zombie. Harper's Magazine 52-61.

2. Centre for Addiction and Mental Health (2008) Methadone saves lives. $\mathrm{CAMH}$, Toronto, Canada.

3. Bergschmidt V (2004) Pleasure, Power and Dangerous Substances: Applying Foucault to the Study of 'Heroin Dependence' in Germany. Anthropol Med 11: 59-73.

4. Bourgois P, Schonberg J (2009) Righteous Dopefiend. University of California Press, Berkley, USA.
5. Butler J (1997) The Psychic Life of Power: Theories in Subjection. Stanford University Press, Stanford California, United States.

6. Fitzgerald JL, Threadgold T (2004) Fear of sense in the street heroin market. International Journal of Drug Policy 15: 407-417.

7. Smith CBR (2010) Socio-spatial stigmatization and the contested space of addiction treatment: Remapping opposition to the disorder of drugs. Soc Sci Med 70: 859-866.

8. Smith CBR (2011) A users' guide to 'juice bars' and 'liquid handcuffs': Fluid negotiations of subjectivity, space and the substance of methadone treatment. Space Cult 14.

9. Turner V (1969) The Ritual Process: Structure and Anti-Structure. Middlesex: Penguin Books.

10. Shildrick M (2002) Embodying the Monster: Encounters with the Vulnerable Self. SAGE Publications, London, United Kingdom.

11. Ronell A (1992) Crack Wars: Literature, Addiction, Mania. University of Nebraska Press, Lincoln, United States.

12. Stewart K (2007) Ordinary Affects. Duke University Press, Durham, USA.

13. Lauro SJ, Embry K (2008) A Zombie Manifesto: The Nonhuman Condition in the Era of Advanced Capitalism. Boundary 2 35: 85-108.

14. Haraway D (2004) The promise of monsters: A regenerative politics for inappropriate/d others. In the Haraway Reader, Routledge, New York, 83-124.

15. Haraway D (1991) Simians, cyborgs and women: The reinvention of nature. Routledge, New York.

16. Alexander BK (2008) The Globalization of Addiction: A Study in Poverty of the Spirit. Oxford University Press, New York, USA.

17. Brodie JF, Redfield M (2002) Introduction. In: JF Brodie, M Redfield, High anxieties: Cultural studies in addiction. University of California Press, Berkeley, USA, 1-16.

18. Kirkup G, Janes L, Woodward K, Houvendon F (2000) The gendered cyborg: A reader. Routledge, New York, USA.

19. Deleuze G (1995) Postscript on Control Societies. In: Negotiations: M Joughin (Trans), Columbia University Press, New York, 177-182.

20. (2002) Fighting for our lives: An anarchist primer. Crimethinc.

21. Smith CBR (2012) Harm reduction as anarchist practice: A users' guide to capitalism and addiction. Critical Public Health 22: 209-221.

22. Smith CBR (2016) Direct action and drug-related harm: Affinity-based tactics in the founding and development of the north american harm reduction movement. Arch Addict Rehabil 1: 1-10.

23. Bey H (1985) T.A.Z: The temporary autonomous zone, ontological anarchy, poetic terrorism. Autonomedia, New York.

24. Day RJF (2004) From hegemony to affinity: The political logic of the newest social movements. Cultural Studies 18: 716-748.

25. Graeber D (2002) The new anarchists. The New Left Review 13: 61-73.

26. Fairbanks RP (2009) How it Works: Recovering Citizens in Post-Welfare Philadelphia. The University of Chicago Press, Chicago. 
27. Cheng R, Smith CBR (2009) Engaging people with lived experience for better health outcomes: Collaboration with mental health and addiction service users in research, policy, and treatment.

28. Smith CBR (2016) Addiction, modernity and the city: A users' guide to urban space (advances in sociology series \#163). Routledge, New York.

29. Szasz Thomas (1992) Bad Habits are not Diseases. In: Arnold S Trebach, Kevin B Zeese, Friedman \& Szasz On liberty and drugs: Essays on the free market and prohibition. The Drug Policy Foundation Press, Washington, D.C 127-131.

30. Granfield R (2004) Addiction and Modernity: A Comment on a Global Theory of Addiction. Nordic Studies on Alcohol and Drugs 44: 27-32.

31. Dole Vincent $P$, Marie E Nyswander (1967) Heroin addiction-a metabolic disease. Arch Intern Med 120: 19-24.

32. Centre for Addiction and Mental Health (2009) Methadone Maintenance Treatment: A Community Planning Guide. Toronto, Canada.

33. Lilly R, Quirk A, Rhodes T, Stimson GV (2000) Sociality in methadone treatment: Understanding methadone treatment and service delivery as a social process. Drugs: Education, Prevention and Policy 7: 163-178.

34. Bourgois $P(2000)$ Disciplining addictions: The bio-politics of methadone and heroin in the united states. Cult Med Psychiatry 24: 165-195.

35. Keane H (2009) Foucault on methadone: Beyond biopower. Int J Drug Policy 20: 450-452.

36. Valentine k (2007) Methadone Maintenance Treatment and Making Up People. Sociology 41: 497-514.

37. Fraser S (2006) The chronotope of the queue: Methadone maintenance treatment and the production of time, space and subjects. International Journal of Drug Policy 17: 192-202.

38. Fraser S, Valentine k (2008) Substance and substitution: Methadone subjects in liberal societies. Palgrave Macmillan, New York.

39. Holt M (2007) Agency and dependency within treatment: Drug treatment clients negotiating methadone and antidepressants. Soc Sci Med 64: 1937-1947.

40. Alexander BK (2000) The Globalization of Addiction. Addiction Research 8: 501-526.

41. Reith G (2004) Consumption and its discontents: Addiction, identity and the problem of freedom. Br J Sociol 55: 283-300.

42. Sedgwick EK (1993) Epidemics of the Will. Tendencies. Duke University Press, Durham, 130-142.

43. Smith CBR (2011) The intoxication of narcotic modernity: Cyborg subjectivity, urban space and the media/technology of substance. Journal of Transgressive Culture 1: 47-84.

44. Harvey D (1997) Social processes and spatial form: An analysis of the conceptual problems of urban planning. In: $\mathrm{N}$ Jewson, S MacGreggor, Transforming Cities: Contested Governance and New Spatial Divisions. Routledge, New York, 19-27.

45. Huyssen Andreas (2003) Present Pasts: Urban Palimpsests and the Politics of Memory. Stanford University Press, Stanford.

46. Hall D (2011) Varieties of zombieism: Approaching comparative political economy through 28 days later and wild zero. International Studies Perspectives 12: 1-17.
47. Harman C (2009) Zombie Capitalism: Global Crisis and the Relevance of Marx. Haymarket Books, Chicago.

48. Courtwright D, Joseph H, Des Jarlais D (1989) Addicts who survived: An oral history of narcotic use in America, 19231965. University of Tennessee Press, Knoxville, TN.

49. Foucault Michel (1977) Discipline and Punish: The Birth of the Prison. Translated by Alan Sheridan. Vintage Books, New York.

50. Koester S, Anderson K, Hoffer L (1999) Active heroin injectors' perceptions and use of methadone maintenance treatment: Cynical performance of self-prescribed risk reduction? Subst Use Misuse 34: 2135-2153.

51. Hunt DE, Lipton DS, Goldsmith DS, Strug DL, Spunt B (1985) "It takes your heart": The image of methadone maintenance in the addict world and its effects on recruitment into treatment. Int J Addict 20: 1751-1771.

52. Rodner S (2005) "I am not a drug abuser, I am a drug user": A discourse analysis of 44 drug users' construction of identity. Addiction Research and Theory 13: 333-346.

53. Mclntosh J, McKeganey N (2000) addicts' narratives of recovery from drug use: Constructing a non-addict identity. Soc Sci Med 50: 1501-1510.

54. Ning AM (2005) Games of truth: Rethinking conformity and resistance in narratives of heroin recovery. Med Anthropol 24: 349-382.

55. Magura S, Rosenblum A (2001) Leaving methadone treatment: lessons learned, lessons forgotten, lessons ignored. Mt Sinai J Med 68: 62-74.

56. Breen CL, Harris SJ, Lintzeris N, Mattick RP, Hawken L, et al. (2003) Cessation of methadone maintenance treatment using buprenorphine: Transfer from methadone to buprenorphine and subsequent buprenorphine reductions. Drug Alcohol Depend 71: 49-55.

57. Calsyn DA, Malcy JA, Saxon AJ (2006) Slow tapering from methadone maintenance in a program encouraging indefinite maintenance. Journal of Substance Abuse Treatment 30: 159-163.

58. Gossop M, Marsden J, Stewart D, Treacy S (2001) Outcomes after methadone maintenance and methadone reduction treatments: Two-year follow-up results from the national treatment outcome research study. Drug Alcohol Depend 6: 255-264.

59. Hiltunen AJ, Eklund C (2002) Withdrawal from methadone maintenance treatment: Reasons for not trying to quit methadone. Eur Addict Res 8: 38-44.

60. Kornor H, Waal H (2005) From opioid maintenance to abstinence: a literature review. Drug Alcohol Rev 24: 267-274.

61. Latowsky M (1996) Improving detoxification outcomes from methadone maintenance treatment: The interrelationship of affective states and protracted withdrawal. J Psychoactive Drugs 28: 251-257.

62. Lenne M, Lintzeris N, Breen C, Harris S, Hawken L, et al. (2001) Withdrawal from methadone maintenance treatment: Prognosis and participant perspectives. Aust $\mathrm{N} \mathrm{Z} \mathrm{J}$ Public Health 25: 121-125.

63. Noble A, Best D, Man L, Gossop M, Strang J (2002) Self-detoxification attempts among methadone maintenance patients: What methods and what success? Addict Behav 27: 575-584.

64. Stall R, Biernacki P (1986) Spontaneous remission from the problematic use of substances: An indicative model derived 
from a comparative analysis of the alcohol, opiate, tobacco, and food/obesity literature. Int J Addict 21: 1-23.

65. Jackson JE (2005) Stigma, liminality, and chronic pain: Mind-body borderlands. American Ethnologist 32: 332-353.

66. Shields R (1990) The 'System of Pleasure': Liminality and the Carnivalesque at Brighton. Theory, Culture and Society 7: $39-72$.

67 . Beech N (2011) Liminality and the practice of identity reconstruction. Human Relations 64: 285-302.

68. Szakolczai A (2009) Liminality and Experience: Structuring transitory situations and transformative events. International Political Anthropology 2: 141-172.

69. Thomassen B (2009) The uses and meanings of liminality. International Political Anthropology 2: 5-27.

70. Whetstone M (2007) Corktown: The panic in needle park. The Globe and Mail, M4.

71. Mitman H (2010) Methadone gets its own beat on Girard Ave. Fishtown Star, 1.

72. Boothroyd D (2006) Culture on Drugs: Narco-Cultural Studies of High Modernity. Manchester University Press, Manchester, England.

73. Boothroyd D (2000) Deconstruction and drugs: A philosophical/literary cocktail. In: N Royle, Deconstructions: A User's Guide. Palgrave, New York, 44-63.

74. Brook H, Stringer R (2005) Users, using, used: A beginners' guide to deconstructing drug discourse. International Journal of Drug Policy 16: 316-325.

75. Derrida J (1993) The rhetoric of drugs: An interview. (M Israel, Trans.). Differences: A Journal of Feminist Cultural Studies 5: 1-12.

76. Centre for Addiction and Mental Health (2008) Methadone Maintenance Treatment. Client Handbook (Revised Edition) $\mathrm{CAMH}$, Toronto, Canada.

77. Houborg E (2012) The political pharmacology of methadone and heroin in danish drug policy. Contemporary Drug Problems 39: 155-192.

78. Sutter AG (1966) The world of the righteous dope fiend Issues in Criminology 2: 177-222.

79. Radcliffe P, Stevens S (2008) Are drug treatment services only for 'thieving junkie scumbags'? drug users and the management of stigmatised identities. Soc Sci Med 67: 1065-1073.

80. Amato L, Davoli M, Minozzi S, Ferri E, Ali R, et al. (2013) Methadone at tapered doses for the management of opioid withdrawal. Cochrane Database Syst Rev.

81. Craig WJ (2007) Harm Reduction is Cunning Nonsense. Canadian Justice Review Board.

82. Mbembe A (2003) Necropolitics. (L. Meintjes, Trans) Public Culture 15: 11-40.
83. McLean K (2011) The biopolitics of needle exchange in the united states. Crit Public Health 21: 71-79.

84. Allman D, Myers T, Schellenberg J, Strike C, Cockerill R (2006) Peer networking for the reduction of drug-related harm. International Journal of Drug Policy 17: 402-410.

85. Canadian HIVIAIDS Legal Network (2005) Nothing about us without us; Greater, Meaningful Involvement of People Who Use Illegal Drugs: A Public Health, Ethical, and Human Rights Imperative. ( ${ }^{\text {nd }}$ edn), Canadian HIVIAIDS Legal Network, Toronto, Canada.

86. Friedman SR, Maslow C, Bolyard M, Sandoval M, Mateu-Gelabert P, et al. (2004) Urging others to be healthy: 'Intravention' by injection drug users as a community prevention goal. AIDS Educ Prev 16: 250-263.

87. Friedman SR, de Jong W, Rossi D, Touzé G, Rockwell $\mathrm{R}$, et al. (2007) Harm reduction theory: Users' culture, micro-social indigenous harm reduction, and the self-organization and outside-organizing of users' groups. Int J Drug Policy 18: 107-117.

88. Kerr T, Small W, Peeace W, Douglas D, Pierre A, et al. (2006) Harm reduction by a 'user-run' organization: A case study of the Vancouver Area Network of Drug Users (VANDU). International Journal of Drug Policy 17: 61-69.

89. Latkin CA (1998) Outreach in natural settings: The use of peer leaders for HIV prevention among injecting drug users' networks. Public Health Rep 113: 151-159.

90. Vaneigem R (1983) The Revolution of Everyday Life (D. Nicholson-Smith, Trans). Rebel Press, London.

91. Cocteau J (2001) Opium: The Diary of His Cure. (M. Crosland, Trans.). Peter Owen Publishers, London.

92. Goldsmith DS, Hunt D, Lipton D, Strug D (1984) Methadone Folklore: Beliefs About Side Effects and Their Impact on Treatment. Human Organization 43: 330-340.

93. North American Opiate Medication Initiative (2006) Backgrounder.

94. Oviedo-Joekes E, Guh D, Brissette S, Marsh DC, Nosyk B, et al. (2010) Double-blind injectable hydromorphone versus diacetylmorphine for the treatment of opioid dependence. $J$ Subst Abuse Treat 38: 408-411.

95. Banbery J, Wolff K, Raistrick D (2000) Dihydrocodeine: A useful tool in the detoxification of methadone-maintained patients. J Subst Abuse Treat 19: 301-305.

96. Alper KR, Lotsof HS, Kaplan CD (2008) The ibogaine medical subculture. J Ethnopharmacol 115: 9-24.

97. Fox KJ (1999) Ideological implications of addiction theories and treatment. Deviant Behavior: An Interdisciplinary Journal 20: 209-232.

98. Romero GA (1978) Dawn of the Dead [Motion Picture]. Laurel Group, United States. 